\title{
REVIEW
}

\section{Acetabular labrum and its tears}

\section{A A Narvani, E Tsiridis, C C Tai, P Thomas}

Groin pain is a major cause of morbidity in athletes. Only in the last decade have acetabular labrum tears been recognised as a possible diagnosis. Awareness of this condition is important for appropriate management. The basic science and pathological and clinical features of acetabular labrum tears are reviewed, and diagnostic and treatment options are presented.

G roin pain is a significant cause of morbidity in athletes. There have been numerous studies on causes of groin pain in athletes such as adductor strains, hernias, iliopsoas related pathology, referred back pain, and osteitis pubis. ${ }^{1-3}$ Although first reported in $1957,{ }^{4}$ it is only in the last decade that acetabular labrum tears have become recognised as a cause of groin pain. In a recent study, they were found to be the cause of groin pain in more than $20 \%$ of athletes presenting with groin pain. ${ }^{5}$ Awareness of this condition among sport clinicians is of great importance, as clinical suspicion of the condition would lead to appropriate management, especially in athletes who have not responded to treatment designed for the more familiar causes of groin pain. The purpose of this paper is to review the basic science and pathological and clinical features of acetabular labrum tears. The diagnostic and therapeutic options for this condition are also presented.

\section{ANATOMY}

The labrum is a fibrocartilaginous rim which encompasses the circumference of the acetabulum, effectively deepening the socket. ${ }^{6}$ It varies greatly in form and thickness. It has three surfaces: an internal articular surface, an external surface contacting the joint capsule, and a basal surface attached to the acetabular bone and transverse ligaments. ${ }^{7}$ Its distal edge is free, forming the lateral limit of the acetabulum. Anteriorly the labrum is equilaterally triangular in radial section. Posteriorly it is more bulbous and lip like, dimensionally square but with a rounded distal surface.

See end of article for authors' affiliations

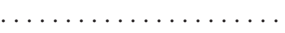

Correspondence to: Dr Narvani, 69a Frognal, London NW3 6YA, UK alinarvani@hotmail.com

Accepted

20 October 2002

\section{HISTOLOGY}

Most of the labrum is composed of thick, type I collagen fibre bundles principally arranged parallel to the acetabular rim, with some fibres scattered throughout this layer running obliquely to the predominant fibre orientation. Seldes et al ${ }^{8}$ investigated the histological features of the acetabular labrum by studying 55 embalmed and 12 fresh frozen adult hips with a mean age of 78 years. They reported that the acetabular labrum merges with the articular hyaline cartilage of the joint surface of the acetabulum through a transition zone of $1-2 \mathrm{~mm}$. A consistent thin tongue of bone extends from the edge of the bony acetabulum into the substance of the labrum. They also showed that the labrum is attached firmly to the articular side of this bony extension by a zone of calcified cartilage with a well defined tidemark, and a narrow synovial lined recess separates the labrum from the capsule. The lining of the cleft consists of highly vascularised, loose connective tissue and fat. ${ }^{8}$

\section{NERVE SUPPLY}

In a study using immunohistochemical techniques in acetabular labra from 24 fresh human cadavers, free nerve endings were seen in all parts of the acetabular labrum; however, they seemed to be more numerous in the superior and anterior quarters. ${ }^{9}$ The authors suggested that these nerve endings may well be involved in nociceptive and proprioceptive mechanisms. Therefore, in the same way that lesions of the meniscus in the knee can stimulate pain fibres, nerve endings also exist for the acetabular labrum lesions to cause pain.

\section{FUNCTION}

As one form of treatment for labrum tears is surgical removal, the function of the labrum needs to be fully evaluated to avoid similar chronic problems to those faced by patients who have had knee menisectomies. The acetabular labrum deepens the hip socket in a fashion that is similar to the way the glenoid labrum deepens the socket. However, in contrast with the glenoid in the glenohumeral joint, the osseous acetabulum in the hip is much deeper and provides substantial stability to the hip joint. The deepening of the acetabulum that is provided by the labrum is therefore thought to be less important. The labrum, however, may enhance stability by providing negative intra-articular pressures in the hip joint upon joint distraction (by partially sealing the joint $).{ }^{10}$ Besides improving the stability of the joint, the sealing function of the labrum enhances a fluid film lubrication mechanism, prevents direct contact of the joint surfaces, and distributes the applied force more evenly across the cartilage surface. ${ }^{11}$

The role of the acetabular labrum in load transmission was further examined in a biomechanical study by Konrath's team in 1998. ${ }^{12}$ The distribution of contact area and pressure between the acetabulum and the femoral head was measured

Abbreviations: $M R I$, magnetic resonance imaging; $M R a$, magnetic resonance arthrography 
Table 1 Classification of labral tears

\begin{tabular}{ll}
\hline $\begin{array}{l}\text { Radial flap } \\
\text { (most common) }\end{array}$ & $\begin{array}{l}\text { Disruption of the free margin of the labrum with subsequent formation of discrete } \\
\text { flap }\end{array}$ \\
$\begin{array}{l}\text { Radial fibrillated } \\
\text { margins of the labrum. More common with degenerative tears }\end{array}$ \\
$\begin{array}{l}\text { Longitudinal peripheral } \\
\text { Unstable }\end{array}$ & $\begin{array}{l}\text { Of variable length along the acetabular insertion of the labrum } \\
\text { Subluxing labra, a reflection of abnormal function rather than shape. }\end{array}$
\end{tabular}

in cadaver hips before and after removal of the acetabular labrum. No appreciable changes with regard to contact area, load, and mean pressure were noted after removal of the labrum. From these findings they concluded that removal of the acetabular labrum does not predispose to premature hip osteoarthritis.

\section{ACETABULAR LABRUM TEARS Causes}

Whereas the torn meniscus is a common cause of mechanical symptoms in the knee, the torn acetabular labrum, until recently, had received little attention as a cause of mechanical hip pain. Previous studies indicate that the acetabular labrum tear is a common finding in the aging adult hip and may occur as part of the degeneration process. ${ }^{813} 14$ Acetabular labrum tears have also been associated with posterior dislocation of the hip and acetabular dysplasia. ${ }^{45}$ There have also been several studies linking acetabular labrum tears to trauma. ${ }^{16-18}$ In these studies, although traumatic injuries ranged from a poorly defined incident occurring in a road traffic accident to a simple twisting injury, most were relatively minor injuries from running, twisting, slipping, and falling.

\section{Epidemiology}

Epidemiological studies have shown that labral tears occur in both sexes with the same frequency. They are also seen in all age groups. ${ }^{16171920}$

\section{Pathology}

In the last 15 years, there have been numerous studies on the location and anatomical features of acetabular labrum tears, including cadaver, arthroscopic, and magnetic resonance imaging (MRI) studies. ${ }^{15-24}$ Most suggest that the tear occurs most commonly in the anterior part of the labrum, especially the anterosuperior quadrant, but the posterior part may also be affected. Seldes et al ${ }^{8}$ have classified the tears into type 1 and type 2 on the basis of their anatomical and histological features. Type 1 tears consist of detachment of the labrum from the articular cartilage surface. These tears tend to occur at the transition zone between the fibrocartilaginous labrum and the articular hyaline cartilage. They are perpendicular to the articular surface and, in some cases, extend to the subchondral bone. Type 2 tears consist of one or more cleavage planes of variable depth within the substance of the labrum. Both types of tear are associated with chondrocyte proliferation and hyalinisation of the labral fibrocartilage along the edges of the defect. Myxoid changes and cystic spaces in the fibrocartilaginous substance of the labrum are also seen in some cases. All labral tears are associated with increased microvascularity within the substance of the labrum at the base of the tear adjacent to the labrum's attachment to bone. Osteophyte formation is also sometimes seen within the labral tears.

Lage et $a l^{18}$ have provided a more comprehensive morphological classification for labral tears based on arthroscopy of 267 hips (table 1).

\section{Clinical features}

Clinical features of acetabular labrum tears have been studied extensively over the last 15 years. ${ }^{15-25}$ These studies suggest that labral tears may have a variety of clinical presentations associated with a wide degree of clinical findings. There may or may not be a history of trauma. In the presence of a recalled incident, the trauma can vary from severe to very mild such as twisting or falling. The injury is usually caused by the hip joint being stressed in rotation. The pain is mainly in the groin, but could be in the trochanteric and buttock region. It could have an acute onset or be gradual. It is common for it to be sharp with a clicking and catching sensation. It could also be associated with a sensation of locking in the hip joint. Activities that involve force adduction of the hip joint in association with rotation in either direction tend to aggravate the pain.

On examination, range of motion may not be limited but there may be pain at the extremes. There are a number of clinical tests, but generally speaking the combined movement of flexion and rotation causes pain in the groin. More precisely, the specific manoeuvres that may cause pain in the groin include:

- flexion, adduction, and internal rotation of the hip joint (with anterior superior tears) ${ }^{17} 20$

- passive hyperextension, abduction, and external rotation (with posterior tears) $)^{17} 20$

- acute flexion of the hip with external rotation and full abduction, followed by extension, abduction, and internal rotation (anterior tears) ${ }^{19}$

- extension, abduction, and external rotation brought to a flexed, adducted, and internally rotated position (posterior tears $)^{19}$

The above manoeuvres may also produce clicking and locking sensations.

\section{Investigations}

As acetabular labrum tears have become recognised as a cause of hip and groin pain, there has been a growing interest in the search for a suitable diagnostic tool. The investigations that have been assessed as diagnostic tools include plain radiography, computerised tomography, conventional arthrography, MRI, magnetic resonance arthrography (MRa), and hip arthroscopy.

Although plain radiographs and computed tomography may show hip dysplasia, arthritis, and acetabular cysts in patients with acetabular labrum tears, they could not be counted as reliable tools for diagnosing the condition itself. $^{15-17} 202124-26$ Even when arthrograms are obtained as well, there does not seem to be an appreciable improvement in the ability of these investigations to detect labral tears. ${ }^{26}$ They are, however, useful for excluding other types of hip pathology. MRI, by virtue of its superior soft tissue contrast and ability to directly depict the labrum, has begun to show promise in detecting labral tears over the last two decades. ${ }^{26}$ MRI features that may suggest a labral tear include irregular labrum shape, a non-triangular labrum, a thickened labrum with no labral recessus, labrum with increased signal intensities on the Tl images, and a labrum that has detached from the acetabulum. 
Table 2 Magnetic resonance arthrographic classification of labral tears

Stage 0 Labra have homogeneous low signal intensity, a triangular shape, and a continuous attachment to the lateral margins of the acetabulum without a notch or a sulcus. There is a recess between the joint capsule and the labrum, a so-called labral recessus, which consists of a linear collection of the contrast material extending between the cranial margin of the acetabular labrum and the joint capsule

Stage 1A Labra have an area of increased signal intensity in the centre which does not extend to the margins, a triangular shape, and a continuous attachment to the lateral margin of the acetabulum without the sulcus. A normal labral recessus is also present

Stage 1B Labra are similar to stage 1A except that they are thickened and no labral recessus is present

Stage 2A There is an extension of contrast material into the labra without detachment from the acetabulum; they are triangular and have a labral recessus

Stage $2 B$ Same as stage 2A except that they are thickened and the labral recessus is not present

Stage $3 \mathrm{~A}$ Labra are detached from the acetabulum but are triangular in shape

Stage 3B Labra are thickened and detached from the acetabulum

Some believe that diagnostic confidence with conventional MRI is limited by the normal variability in labral size and shape, by the joint capsule collapsed against the acetabular rim, and by difficulties in distinguishing tears of the labrum from the pseudotears caused by normal articular cartilage. ${ }^{23} 26$ Indeed, when MRI features are compared with arthroscopic findings in patients with suspected tears, it does become apparent that MRI on its own is not a reliable tool for detecting a labrum tear. ${ }^{26} 27$

MRa exploits the natural advantages gained from joint effusion. In conventional MRI, it is known that intra-articular structure and abnormalities are better delineated in joints with effusion. ${ }^{28}$ Fluid distends the joint capsule, outlines the acetabular labrum, and fills the tear. Without joint effusion, signal differences between the intra-articular structures may be insufficient to enable the differentiation of normal and abnormal findings. The success of MRa in the shoulder has led many clinicians to assess its suitability for investigating hip pathology. The technique involves direct intra-articular contrast administration into the hip joint. A needle is introduced into the hip joint under sterile conditions with fluoroscopic guidance. Many investigators then use an injection of contrast to confirm the intra-articular needle position. This is followed by injection of gadopentate dimeglumine solution. Magnetic resonance images are then obtained within 30 minutes. ${ }^{28}$

The best description of features of acetabular labrum lesions on MRa is provided by Czerny $\mathrm{et}^{\mathrm{a} \mathrm{l}^{26}}$ in a form of comprehensive classification (table 2).

Several authors have examined the suitability of MRa as a diagnostic tool for labral tears. ${ }^{202325262930}$ Czerny et $a^{26}$ reported their findings on 57 hips in 56 patients who had MRa for clinical suspicion of labral pathology. Surgery was subsequently performed on 22 of these hips. In 20 of them, the MRa findings correlated accurately with surgical findings. The other 35 hips were treated conservatively (MRa showed labral pathology in 31 ). Leunig et $\mathrm{al}^{20}$ assessed prospectively the value of MRa in 23 patients and compared findings with those of surgery. In 21 of the patients, MRa suggested a labral pathology. This was confirmed at operation in 18 of the patients, but there was no abnormality in the other three. Plotz et $a^{29}$ also studied the sensitivity and specificity of MRa for labral pathology by comparing MRa findings with macroscopic and histological findings in 20 cadaver hips. A labrum lesion was detected in 15 on gross histological examination. MRa confirmed the histological findings in nine of the 15 specimens (sensitivity of $60 \%$ ). They reported that there were no false positive findings.

One difficulty when comparing the results of many of these studies is that different combinations of coronal, sagittal, and axial views were used. Plotz et $\mathrm{l}^{31}$ suggested that MRa imaging with radial planes gives greater sensitivity than the traditional oblique coronal and axial. The other problem with many of these studies is the small number of cases used. Clearly more standardised research is required on the suitability of MRa for assessing labral tears.
Hip arthroscopy

Arthroscopic surgery is increasingly used in orthopaedic practice because of the development of minimally invasive diagnostic and therapeutic procedures, particularly for the knee and shoulder. Until recently, arthroscopic management of hip disorders has not received similar attention. The concept of hip arthroscopy was first introduced in 1931 by Burman, but did not resurface in studies in North America until 1977 when Gross reported his experience with arthroscopy of congenitally dislocated hip. ${ }^{32}$ Adaptation of arthroscopic equipment and instruments for the hip joint has since led to safe visualisation and instrumentation of the hip joint.

Hip arthroscopy uses two or three portals. Two are lateral (anterolateral and posterolateral) and one is anterior. Some clinicians perform the procedure with patients on their side, ${ }^{33}$ whereas others have the patient supine. ${ }^{34}$ The portals are exactly the same whether the arthroscopy is performed in the lateral or supine patient position. The entry point for the anterolateral portal starts at the anterior superior tip of the greater trochanter. ${ }^{35}$ Initially a spinal needle is introduced under the image intensifier. The needle is walked up the neck of the femur into the hip joint. Once the needle is in the hip joint, air will be sucked into the joint, allowing it to open further for the passage of the scope. Some authors recommend distension of the joint with $40 \mathrm{ml}$ normal saline. ${ }^{35}$ The posterolateral port is at the superolateral corner of the greater trochanter. The two lateral portal needles are generally passed parallel to each other. When used, the entry point for the anterior port is the junction of the vertical from the anterior superior iliac spine and a horizontal line drawn anteriorly from the superior surface of the femoral greater trochanter.

Both $30^{\circ}$ and $70^{\circ}$ arthroscopes should be available to improve visualisation. It has been reported that the $30^{\circ}$ arthroscope is best for viewing the central portion of the acetabulum and the femoral head and the superior portion of the acetabular fossa, whereas the $70^{\circ}$ scope is best for visualising the periphery of the joint, the acetabular labrum, and the inferior portion of the acetabular fossa. ${ }^{34}$

It is generally agreed that some distraction is necessary to visualise the important intra-articular structure, but there seems to be great variation in the force required to achieve adequate arthroscopic examination (range 25-200 lb) ${ }^{36}$ Some have suggested that, if the distraction forces are kept below 50 $\mathrm{lb}$ for less than two hours, no neuropraxias will occur provided that there is an adequate sized peroneal post with proper padding. ${ }^{37}$ It is further suggested that the forces required to distract the hip joint should be further reduced by the relaxation of muscle tone (by ensuring adequate anaesthesia) and by releasing the resting intra-articular negative pressure by performing joint capsule puncture and injection of normal saline solution. ${ }^{36}$

Hip arthroscopy can be used for both diagnosis and treatment. It allows a comprehensive evaluation of labral anatomy. Visual inspection is possible for all quadrants of the 
joint. In addition, long probes can be used to evaluate subtle or suspected lesion areas, on either the articular surface or the capsular margin. Many authors use it as the main tool in diagnosing labral tears, in particular. ${ }^{18} 213839$ Although a diagnostic hip arthroscopy is indicated in cases where no definite diagnosis can be made using the usual diagnostic tools, its use may be limited by possible complications. These complications are mostly the result of traction and fluid management. ${ }^{37}$ Another potential hazard is the presence of a sensitive neurovascular structure close to the hip joint especially during introduction of arthroscopic instruments. Byrd ${ }^{40}$ found 20 complications $(1.3 \%)$ in 1491 cases reviewed among several experienced surgeons and those reported in literature. The most common complication was pudendal nerve neuropraxias ( six cases) followed by sciatic nerve neuropraxias (four cases). In only one case was there permanent damage to a nervous structure (from laceration of the lateral femoral cutaneous nerve). There were three cases of intra-abdominal fluid extravasation. He also found one case of scrotal necrosis, one retrieved broken instrument, and one case of heterotopic ossification. In a small study involving 19 patients who had hip arthroscopy for various reasons, Funke and Munzinger ${ }^{41}$ were faced with three complications. These were neuropraxia of the pudendal nerve for three weeks, haematoma of the labia majora, and acute onset abdominal pain during the procedure (with regional anaesthesia) because of fluid escaping into the peritoneum. They attributed the first two complications to the poor positioning of the centre bar and insufficient padding of the perineal area while the patients were in the lateral decubitus position.

Sampson ${ }^{37}$ reported 34 complications in 530 hip arthroscopies. There were 20 transient nerve injuries, in which 10 were peroneal, four pudendal, four sciatic, and one patient with both sciatic and femoral. All the neuropraxias occurred in cases where there were prolonged traction times (five to six hours) despite intermittent relief of the traction. All but one of the neuropraxias resolved within three days (one took one week to resolve). He reported intra-abdominal fluid extravasation in nine patients, instrument breakage in two, femoral head scuffing in two, and avascular necrosis in one. Overall, he suggested that significant complication occurred in only three patients $(0.5 \%$ of the cases; two severe femoral head scuffing and one avascular necrosis).

\section{Treatment}

Conservative management of acetabular labrum tears consists of bed rest with or without traction followed by a period of protected weight bearing. ${ }^{19}{ }^{24}$ Although Fitzgerald ${ }^{19}$ reported good outcomes in seven patients with labral tears treated conservatively with crutches for four weeks, there are no studies investigating the long term outcome of conservative management. Labral tears tend to occur on the articular non-vascular edge, and may therefore not heal with conservative treatment. ${ }^{42}$ It is not clear whether an "unhealed" labrum will remain symptomatic or whether it predisposes to early degenerative changes in the hip joint. In many patients, the labrum tear is associated with hip degeneration; however, in these patients the tear may have occurred as a result of degeneration. ${ }^{8} 1415383942$

Arthroscopic debridement of the torn part of the labrum is another means of treatment. ${ }^{18} 19323839$ Several studies have suggested a good outcome in patients treated surgically with arthroscopy. ${ }^{18} 1924323839$ From their experience (37 patients with labral tears), Lage $e t$ a $l^{18}$ reported that partial resection of an isolated traumatic labral tear can improve symptoms in up to $75 \%$ of patients. Farjo $e$ t $a l^{39}$ divided their patients with labral tears into two groups on the basis of the presence of appreciable arthritis on the radiograph. All patients had undergone arthroscopic debridement of the acetabular labral tear. Of those without arthritis, $71 \%$ had good to excellent results at one year follow up. Of those with arthritis, $21 \%$ had good to excellent results. Hase et $a l^{24}$ reported the outcome of arthroscopic debridement of acetabular tears in a small study of eight patients. All eight patients experienced immediate pain relief and were free of symptoms at their latest follow up (range 1 year 3 months to 5 years 8 months). In a prospective study to assess the outcome of arthroscopic debridement of 27 labral tears, Byrd and Jones ${ }^{43}$ found significant improvement in symptoms with a two year follow up. Santori and Villar ${ }^{38}$ reviewed a series of 76 arthroscopic limbectomies for labral tears. The range of the follow up period was 24-61 months. They reported that $67.3 \%$ of the patients were pleased with the result of their operation. O'Leary and coauthors ${ }^{44}$ respectively reviewed 22 patients who had hip arthroscopy for labrum tears. With an average follow up of 30 months, they reported that arthroscopic debridement resolved the mechanical symptoms and significantly decreased pain in 20 of the 22 patients. Byrd and Jones ${ }^{45}$ presented their findings of one of the very few published studies on the outcome of hip arthroscopy in athletes. Twenty seven of the hip arthroscopies showed a labrum pathology. Their average follow up was 26 months. The best outcome was achieved in patients with impinging osteophytes, loose bodies, and ruptured ligamentum teres. Lesser but appreciable outcomes were seen for both chondral and labral pathology. Overall, younger patients, those with a traumatic origin, had a better outcome. It is also interesting that in over two thirds of their patients, eventual improvement was achieved within the first month, with the result plateauing by the third month.

When reviewing the studies on the outcome of hip arthroscopy for acetabular labrum tears, several factors must be considered. Firstly, we still do not fully understand the natural history of the labral tear. Some may heal or at least become symptomatically quiescent without developing secondary degradative consequences. It has been suggested that an anastomic network of vessels penetrate the outermost layer of the labrum on the capsular surface only to a depth of $0.5 \mathrm{~mm}$, leaving most of the labrum avascular. ${ }^{42}$ This absence of appreciable vascularity may prevent intrinsic healing of the labrum once injured. Further research on the natural history of acetabular labrum tears is required, and a randomised controlled trial comparing conservative management with arthroscopic debridement would be useful.

The second factor to be considered is the way the outcome of the hip arthroscopy is evaluated. Some have used the Harris hip score, ${ }^{38434}$ and others have not used any of the recognised outcome assessments..$^{2494}$ The Harris hip score is an imperfect tool for assessing outcome in hip arthroscopy because it was designed to assess hip arthroplasty. Therefore standardised outcome measures designed specifically for hip arthroscopies are needed which future researchers should be encouraged to use.

Thirdly, there is a lack of long term data. The longest follow up seems to be five years, ${ }^{45}$ but most studies have much shorter follow up periods. ${ }^{24} 38394344$ There needs to be further studies with long term follow ups.

\section{SUMMARY}

Causes of groin pain in athletes other than acetabular labrum tears have been extensively studied in the past. Acetabular labrum tears have emerged as a significant source of groin pain in the last decade particularly in athletes. Appropriate management depends on the sport clinician's awareness of its pathological and clinical features and also available diagnostic and therapeutic tools. The role of MRa in its diagnosis needs further clarification. Randomised controlled trials with long term follow up are required to further evaluate the role of arthroscopy in treatment of acetabular labrum tears. Studies performed so far suggest that it is an effective treatment. There should be a high clinical suspicion of acetabular labrum 
tears in athletes with mechanical symptoms and also in those who have not responded to treatment designed for the more familiar causes of groin pain.

\section{References}

1 Anderson K, Strickland SM, Warren R. Hip and groin injuries in athletes. Am J Sports Med 2001;29:521-33.

2 Lovell G. The diagnosis of chronic groin pain in athletes: a review of 189 cases. Aust J Sci Med Sport 1995;27:76-9.

3 Lynch SA, Renstrom PAFH. Groin Injuries in sport. Sports Med 1999;28: 187-44.

4 Paterson I. The torn acetabular labrum: a block to reduction of a dislocated hip. J Bone Joint Surg [Br] 1957;39:306-9.

5 Narvani AA, Tsiridis E, Kendall S, et al. Prevalence of acetabular labrum tears in sports patients with groin pain. Knee Surg Sports Traumatol Arthrosc 2003; in press.

6 Williams PL, ed. In: Gray's anatomy: the anatomical basis of medicine and surgery. 38 edn. New York: Churchill Livingstone, 1995:684.

7 Barnsdale CA. Anatomical, histological and MR features of hip joint. BSc thesis, UCL, 1994.

8 Seldes RM, Tan V, Hunt J, et al. Anatomy, histological features, and vascularity of the adult acetabular labrum. Clin Orthop 2001;382:232-40

9 Kim YK, Azuma H. The nerve endings of the acetabular labrum. Clin Orthop 1995:320:176-81

10 Takechi $\mathbf{H}$, Nagashima $\mathrm{H}$, Ito $\mathrm{S}$. Intra-articular pressure of the hip joint outside and inside the limbus. Journal of the Japanese Orthopedic Association 1982;56:529-36.

11 Ferguson SJ, Bryant JT, Ganz R, et al. The acetabular labrum seal: a poroelastic finite element model. Clin Biomech 2000;15:463-8.

12 Konrath GA, Hamel AJ, Olsen SA, et al. The role of the acetabular labrum and the transverse acetabular ligament in load transmission in hip. J Bone Joint Surg [Am] 1998;80:1781-7.

13 Shibutuni $\mathbf{N}$. Three-dimensional architecture of the acetabular labrum: a scanning electron microscopic study. Journal of the Japanese Orthopedic Association 1988;62:321-9.

14 Byers PD, Contepomi CA, Farkas TA. A post mortem study of the hip joint. Including prevalence of the features of the right side. Ann Rheum Dis 1970;29:15-31.

15 Dorrell JH, Catterall A. The torn acetabular labrum. J Bone Joint Surg [Br] 1986;68:400-3.

16 Ikeda T, Awaya G, Suzuki S, et al. Torn acetabular labrum in young patients: arthroscopic diagnosis and management. J Bone Joint Surg [Br] 1998;70:13-16.

17 Klaue K, Durni CW, Ganz R. The acetabular rim syndrome: a clinical presentation of dysplasia of the hip. J Bone Joint Surg $[\mathrm{Br}]$ 1991;73:423-9.

18 Lage LA, Patel JV, Villar RN. The acetabular labral tear: an arthroscopic classification. Arthroscopy 1996;12:269-72.

19 Fitzgerald RH. Acetabular labrum tears. Diagnosis and treatment. Clin Orthop 1995;311:60-8.

20 Leunig M, Werlen S, Ungersbock A, et al. Evaluation of the acetabulum labrum by MR arthrography. J Bone Joint Surg [Br] 1997;79:230-4.

21 McCarthy JC, Busconi B. The role of hip arthroscopy in the diagnosis and treatment of hip disease. Can J Surg 1995;38:S13-17.
22 Byrd JW. Labral lesions: an elusive source of hip pain: case report and literature review. Arthroscopy 1996;12:603-12

23 Petersilge CA, Haque MA, Petersilge WJ, et al. Acetabular labrum tears: evaluation with MR arthrography. Radiology 1996;200:225-30.

24 Hase T, Ueo T. Acetabular labral tear: arthroscopic diagnosis and treatment. Arthroscopy 1999;15:138-41.

25 Hofmann S, Tschauner C, Urban M, et al. Clinical and radiological diagnosis of lesions of the labrum of the hip. Orthopade 1998:27:681-9.

26 Czerny C, Hofmann S, Neuhold A, et al. Lesions of the acetabular labrum: accuracy of MR arthrography in detection and staging. Radiology 1996;200:225-30.

27 Aydingoz U, Ozturk MH. MR images of the acetabular labrum: a comparative study of both hips in 180 asymptomatic volunteers. Eur Radiol 2001;11:567-74.

28 Palmer WE. MR arthrography of the hip. Semin Musculoskelet Radiol 1998;2:349-61.

29 Plotz GM, Brossmann J, Schunke M, et al. Magnetic resonance arthrography of acetabulum labrum. J Bone Joint Surg $[\mathrm{Br}]$ 2000;82:426-32

30 Hodler J, Yu JS, Goodwin D, et al. MR arthrography of the hip: improved imaging of the acetabular labrum with histological correlation. AJR Am J Roentgenol 1995; 165:887-91

31 Plotz GMJ, Brossmann J, von Knock M, et al. Magnetic resonance arthrography of the acetabular labrum: value of radial reconstruction. Arch Orthop Trauma Surg 2001;121:450-7.

32 Gross R. Arthroscopy in hip disorders in chidren. Orthop Rev 1977:6:43-9.

33 Glick MG. Hip arthroscopy: the lateral approach. Clin Sports Med 2001;20:733-47.

34 Byrd JWD. Hip arthroscopy: the supine position. Clin Sports Med 2001;20:703-31.

35 Sweeney HJ. Arthroscopy of the hip: anatomy and portals. Clin Sports Med 2001;20:697-702.

36 McCarthy JC, Day B, Busconi B. Hip arthroscopy: applications and technique. J Am Acad Orthop Surg 1995;3:115-22.

37 Sampson TG. Complication of hip arthroscopy. Clin Sports Med 2001;20:831-5.

38 Santori N, Villar RN. Acetabular labral tears: results of arthroscopic partial limbectomy. Arthroscopy 2000;16:11-15.

39 Farjo LA, Glick JM, Sampson TG. Hip arthroscopy for acetabular labrum tears. Arthroscopy 1999:15:132-7.

40 Byrd J. Complications associated with hip arthroscopy. In: Byrd J, ed. Operative hip arthroscopy. New York: Thieme, 1998:171-6.

41 Funke EL, Munzinger U. Complications in hip arthroscopy. Arthroscopy 1996;12:156-9.

42 McCarthy JC, Noble PC, Wright J, et al. The role of labral lesions in the development of early degenerative hip disease. American Academy of Orthopaedic Surgery, San Francisco, Poster presentation. 2001.

43 Byrd JW, Jones KS. Prospective analysis of hip arthroscopy with 2-year follow-up. Arthroscopy 2000;16:578-87.

44 O'Leary JA, Berend K, Vail TP. The relationship between diagnosis and outcome in arthroscopy of the hip. Arthroscopy 2001;17:181-8.

45 Byrd JWT, Jones KS. Hip arthroscopy in athletes. Clin Sports Med 2001;20:749-61. 